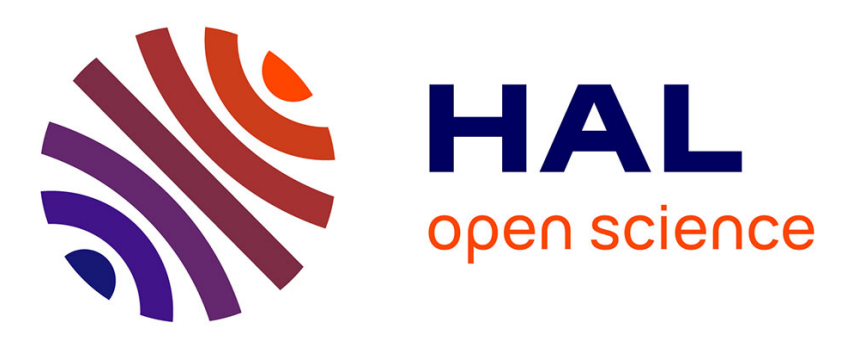

\title{
ASIC1a plays a key role in evoking the metabolic component of the exercise pressor reflex in rats
}

Guillaume P Ducrocq, Joyce S Kim, Juan A Estrada, Marc P Kaufman

\section{To cite this version:}

Guillaume P Ducrocq, Joyce S Kim, Juan A Estrada, Marc P Kaufman. ASIC1a plays a key role in evoking the metabolic component of the exercise pressor reflex in rats. AJP - Heart and Circulatory Physiology, 2020, 318, pp.78 - 89. 10.1152/ajpheart.00565.2019 . hal-02969652

\section{HAL Id: hal-02969652 https://hal.science/hal-02969652}

Submitted on 18 Feb 2021

HAL is a multi-disciplinary open access archive for the deposit and dissemination of scientific research documents, whether they are published or not. The documents may come from teaching and research institutions in France or abroad, or from public or private research centers.
L'archive ouverte pluridisciplinaire HAL, est destinée au dépôt et à la diffusion de documents scientifiques de niveau recherche, publiés ou non, émanant des établissements d'enseignement et de recherche français ou étrangers, des laboratoires publics ou privés. 


\title{
RESEARCH ARTICLE | Integrative Cardiovascular Physiology and Pathophysiology
}

\section{ASIC1a plays a key role in evoking the metabolic component of the exercise pressor reflex in rats}

\author{
(D) Guillaume P. Ducrocq, (1) Joyce S. Kim, Juan A. Estrada, and Marc P. Kaufman \\ Heart and Vascular Institute, Penn State College of Medicine, Hershey, Pennsylvania
}

Submitted 24 September 2019; accepted in final form 28 October 2019

\begin{abstract}
Ducrocq GP, Kim JS, Estrada JA, Kaufman MP. ASIC1 a plays a key role in evoking the metabolic component of the exercise pressor reflex in rats. Am J Physiol Heart Circ Physiol 318: H78-H89, 2020. First published November 1, 2019; doi:10.1152/ ajpheart.00565.2019.-The role of the acid-sensing ion channel 1a (ASIC1a) in evoking the exercise pressor reflex is unknown, despite the fact that ASIC1a is opened by decreases in $\mathrm{pH}$ in the physiological range. This fact prompted us to test the hypothesis that ASIC1a plays an important role in evoking the exercise pressor reflex in decerebrated rats with freely perfused hindlimb muscles. To test this hypothesis, we measured the effect of injecting two ASIC1a blockers into the arterial supply of the triceps surae muscles on the reflex pressor responses to four maneuvers, namely 1) static contraction of the triceps surae muscles (i.e., the exercise pressor reflex), 2) calcaneal tendon stretch, 3) intra-arterial injection of lactic acid, and 4) intra-arterial injection of diprotonated phosphate. We found that the 2 ASIC1a blockers, psalmotoxin-1 (200 ng/kg) and mambalgin-1 (6.5 $\mu \mathrm{g} / \mathrm{kg}$ ), decreased the pressor responses to static contraction as well as the peak pressor responses to injection of lactic acid and diprotonated phosphate. In contrast, neither ASIC1a blocker had any effect on the pressor responses to tendon stretch. Importantly, we found that ASIC1a blockade significantly decreased the pressor response to static contraction after a latency of at least $8 \mathrm{~s}$. Our results support the hypothesis that ASIC1a plays a key role in evoking the metabolic component of the exercise pressor reflex.
\end{abstract}

NEW \& NOTEWORTHY The role played by acid-sensing ion channel 1a (ASIC1a) in evoking the exercise pressor reflex remains unknown. In decerebrated rats with freely perfused femoral arteries, blocking ASIC1a with psalmotoxin-1 or mambalgin-1 significantly attenuated the pressor response to static contraction, lactic acid, and diprotonated phosphate injection but had no effect on the pressor response to stretch. We conclude that ASIC1a plays a key role in evoking the exercise pressor reflex by responding to contractioninduced metabolites, such as protons.

autonomic control; mambalgin; mechanoreflex; metaboreflex; psalmotoxin

\section{INTRODUCTION}

The hemodynamic response to exercise is driven by coordinated neural mechanisms that function to improve blood flow and oxygen delivery to the exercising muscles $(3,43)$. The exercise pressor reflex plays a key role in that response by reflexively increasing arterial blood pressure when muscles contract $(1,11,39,41)$. The afferent arm of this reflex com-

Address for reprint requests and other correspondence: G. Ducrocq, Penn State College of Medicine, Heart and Vascular Inst. C2810, 500 University Dr., Hershey, PA 17033 (e-mail: g.ducrocq@ live.fr). prises slowly conducting group III and IV afferents (39), whose endings originate in the interstitial space of contracting myocytes and their accompanying vessels and tendons (50, $57 \mathrm{a})$. Even though the stimuli that activate the endings of these afferent fibers are polymodal $(30,32,35,40)$, group III afferents appear to be primarily activated by mechanical distortion of their receptive fields, whereas group IV afferents appear to be primarily activated by metabolic byproducts of muscle contraction (32). More specifically, an increase in muscle tension and a decrease in $\mathrm{pH}$ as well as an increase in the concentration of bradykinin, prostaglandin, lactate, and diprotonated phosphate ions during exercise have been highlighted as potent activators of the exercise pressor reflex (24, 25, 31, 32, 35, 44-46, 52, 53).

Although the stimuli that evoke the exercise pressor reflex are well documented, the identification of their target receptors remains unclear. This is especially true for the receptors that detect the exercise-induced decrease in interstitial $\mathrm{pH}$ associated with the increase in lactate and inorganic phosphate concentrations in working muscles. Transient receptor potential vanilloid- 1 opens at a $\mathrm{pH}<5.5$ (12), but conflicting results have been reported regarding the role of this channel in evoking the metabolic component of the exercise pressor reflex $(18,34,42,48,55)$. Another group of channels, acid-sensing ion channels (ASICs), open when exposed to hydrogen ion concentrations within the physiological range. ASICs are composed of seven receptors, namely, ASIC1 $a$ and -b, ASIC $2 a$ and -b, ASIC3, ASIC4, and ASIC5 (23). ASIC1, -2 , and -3 are expressed in dorsal root ganglia $(7,57,58)$, whereas ASIC4 and ASIC5 have been identified in the central nervous system only (22). ASIC1a and ASIC3 are activated by a $\mathrm{pH}$ of 7.0 with $\mathrm{pH}_{50}$ of 6.6 (4); their currents are potentiated by the presence of lactate ions (28, 29). In contrast, ASIC 2 is activated only by hydrogen ion concentrations that exceed the physiological range; for example, the $\mathrm{pH}_{50}$ for ASIC2a is 4.5 (26). Consequently, ASIC1a and ASIC3 appear to be good candidates for playing a role in evoking the metabolic component of the exercise pressor reflex.

Nevertheless, in vivo experiments using APETx2, a selective ASIC3 antagonist, provided only modest support for a role of this channel in evoking the exercise pressor reflex in rats with freely perfused hindlimb muscles $(54,56)$. No data on the effect of ASIC1a blockade on the exercise pressor reflex exist, despite the fact that ASIC1a is opened by a decrease in $\mathrm{pH}$ in the physiological range. The purpose of this study was thus to determine the effect of blocking ASIC1a on the pressor response evoked by static contraction 
Table 1. Pressor and cardioaccelerator responses to intra-arterial injection of chemicals, static contraction, or stretch of the triceps surae muscles

\begin{tabular}{|c|c|c|c|c|c|c|}
\hline & $n$ & Baseline & Peak & $95 \% \mathrm{CI}$ & $P$ Value & Cohen's $d$ \\
\hline Lactic acid & 11 & & & & & \\
\hline MAP, mmHg & & $111 \pm 23$ & $159 \pm 38$ & [32:64] & $<0.001$ & 1.64 \\
\hline $\mathrm{HR}$, beats/min & & $364 \pm 32$ & $368 \pm 33$ & [4:6] & $<0.001$ & 2.27 \\
\hline $\mathrm{MAP}, \mathrm{mmHg}$ & & $124 \pm 16$ & $167 \pm 36$ & {$[27: 61]$} & $<0.001$ & 1.40 \\
\hline HR, beats/min & & $332 \pm 48$ & $338 \pm 47$ & [3:9] & $<0.010$ & 0.87 \\
\hline Static contraction & 22 & & & & & \\
\hline Stretch & 11 & & & & & \\
\hline MAP, mmHg & & $123 \pm 19$ & $161 \pm 20$ & {$[23: 55]$} & $<0.001$ & 1.41 \\
\hline $\mathrm{HR}$, beats/min & & $336 \pm 50$ & $340 \pm 50$ & {$[3: 6]$} & $<0.001$ & 0.57 \\
\hline $\mathrm{BPI}, \mathrm{mmHg} \cdot \mathrm{s}$ & & $3,579 \pm 665$ & $4,005 \pm 555$ & [213:639] & $<0.001$ & 1.01 \\
\hline
\end{tabular}

Values are means $\pm \mathrm{SD} ; n$, sample size. A $95 \%$ confidence interval is presented as the lower and upper boundary of the interval containing the true value of the effect of stimulus on the corresponding index. BPI, blood pressure index; CI, confidence interval; HR, heart rate; MAP, mean arterial blood pressure.

in decerebrated rats with freely perfused hindlimbs. In addition, we did not expect ASIC1a to play a role in the pressor response to stretch, which is mainly determined by mechanoreceptors (51). We therefore also verified the effect of ASIC1a blockade on the pressor response evoked by tendon stretch to control for potential off-target effects. We hypothesized that 1 ) blocking ASIC1a reduces the pressor response to static contraction, 2) blocking ASIC1a has no effect on the pressor response to passive stretch, 3) blocking ASIC1a reduces the peak pressor response to injection of lactic acid, and 4) blocking ASIC1a reduces the peak pressor response to injection of diprotonated phosphate.

\section{METHODS}

\section{Ethical Approval}

The Institutional Care and Use Committee of the Penn State College of Medicine approved all of the procedures. The authors understand and conformed to the ethical guidelines of the journal for animal use in research.
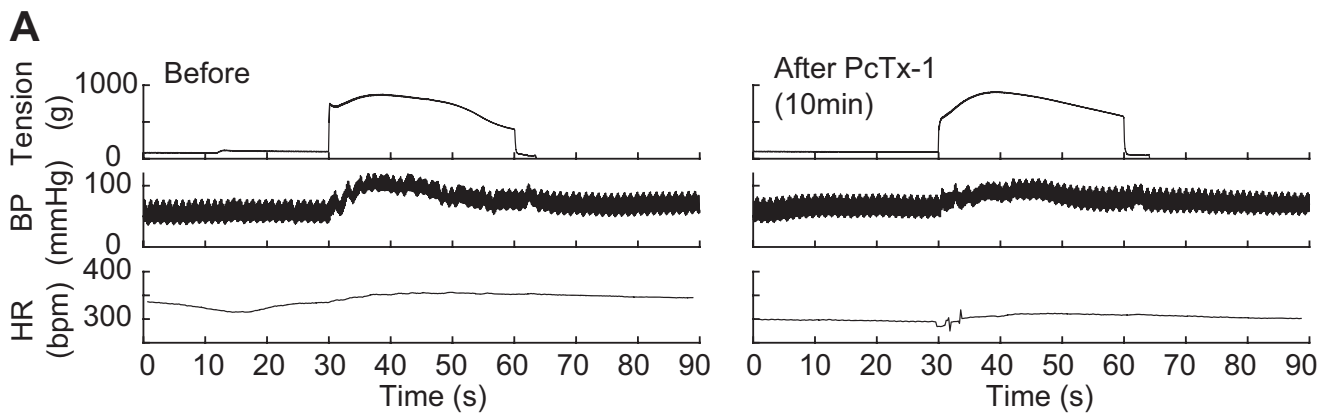

B

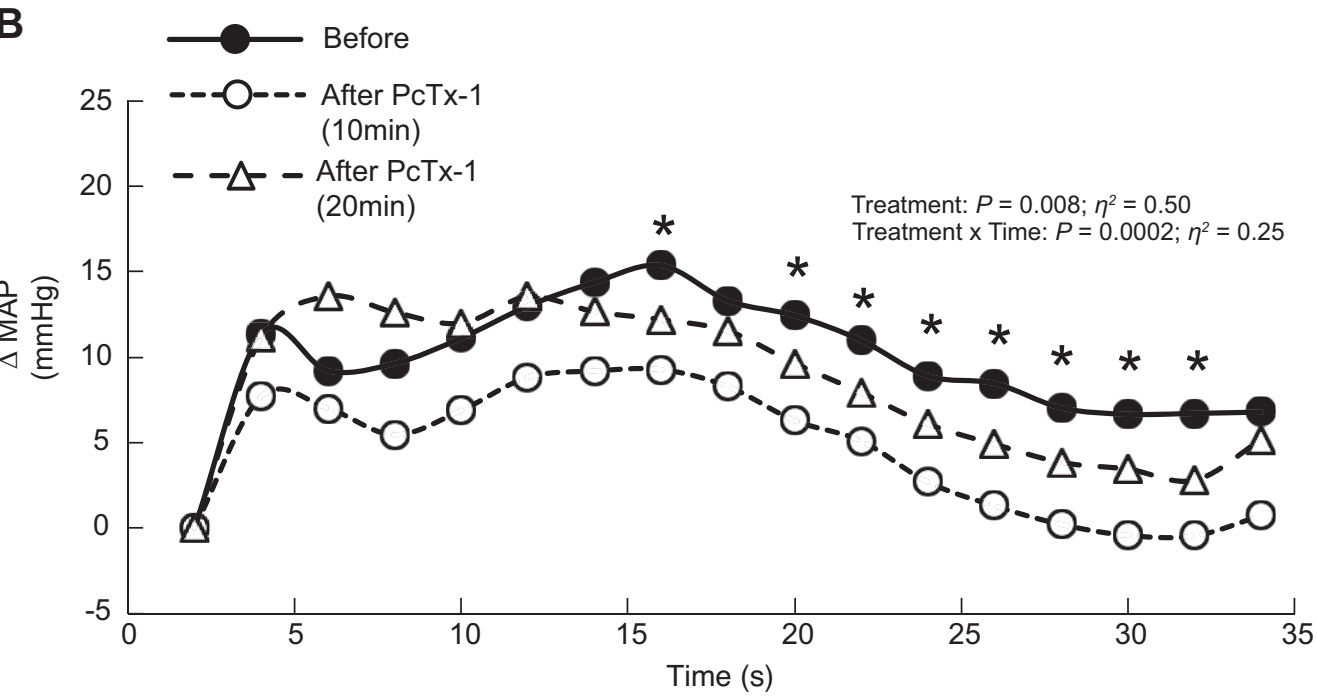

Fig. 1. Representative traces and time course of the pressor response to static contraction before and after psalmotoxin-1 (PcTx-1) injection. Acid-sensing ion channels $1 \mathrm{a}$ were antagonized by injecting PcTx-1 ( $n=8 ; 200 \mathrm{ng} /$ $\mathrm{kg}, 100 \mu \mathrm{L}$ ) into the superficial epigastric artery. $A$ : representative traces of the pressor responses to contraction before and 10 min after PcTx-1 in the same rat. $B$ : averaged time course of the pressor response to contraction, which was evoked before, at $10 \mathrm{~min}$ after, and at $20 \mathrm{~min}$ after PcTx-1. Averaged time course of blood pressure includes $2 \mathrm{~s}$ of baseline, $30 \mathrm{~s}$ of contraction, and $2 \mathrm{~s}$ after the end of contraction. For clarity, error bars were omitted. ${ }^{*} P<0.05$, significant difference between before and 10 min after PcTx-1. BP, blood pressure; bpm, beats/min; HR, heart rate; MAP, mean arterial pressure. 
A

Fig. 2. Representative traces and time course of the pressor response to static contraction before and after mambalgin-1 (Mamb-1) injection. Acid-sensing ion channels 1a were antagonized by injecting Mamb-1 $(n=5 ; 6.5 \mu \mathrm{g} / \mathrm{kg}, 100 \mu \mathrm{L})$ into the superficial epigastric artery. $A$ : representative traces of pressor responses to contraction before and $10 \mathrm{~min}$ after Mamb-1 in the same rat. $B$ : averaged time course of the pressor response to contraction, which was evoked before, at 10 after, and at $20 \mathrm{~min}$ after Mamb-1. The averaged time course of blood pressure includes $2 \mathrm{~s}$ of baseline, $30 \mathrm{~s}$ of contraction, and $2 \mathrm{~s}$ after the end of contraction. For clarity, error bars were omitted. $* P<$ 0.05 , significant difference between before and 10 min after Mamb-1. BP, blood pressure; bpm, beats/min; HR, heart rate; MAP, mean arterial pressure.
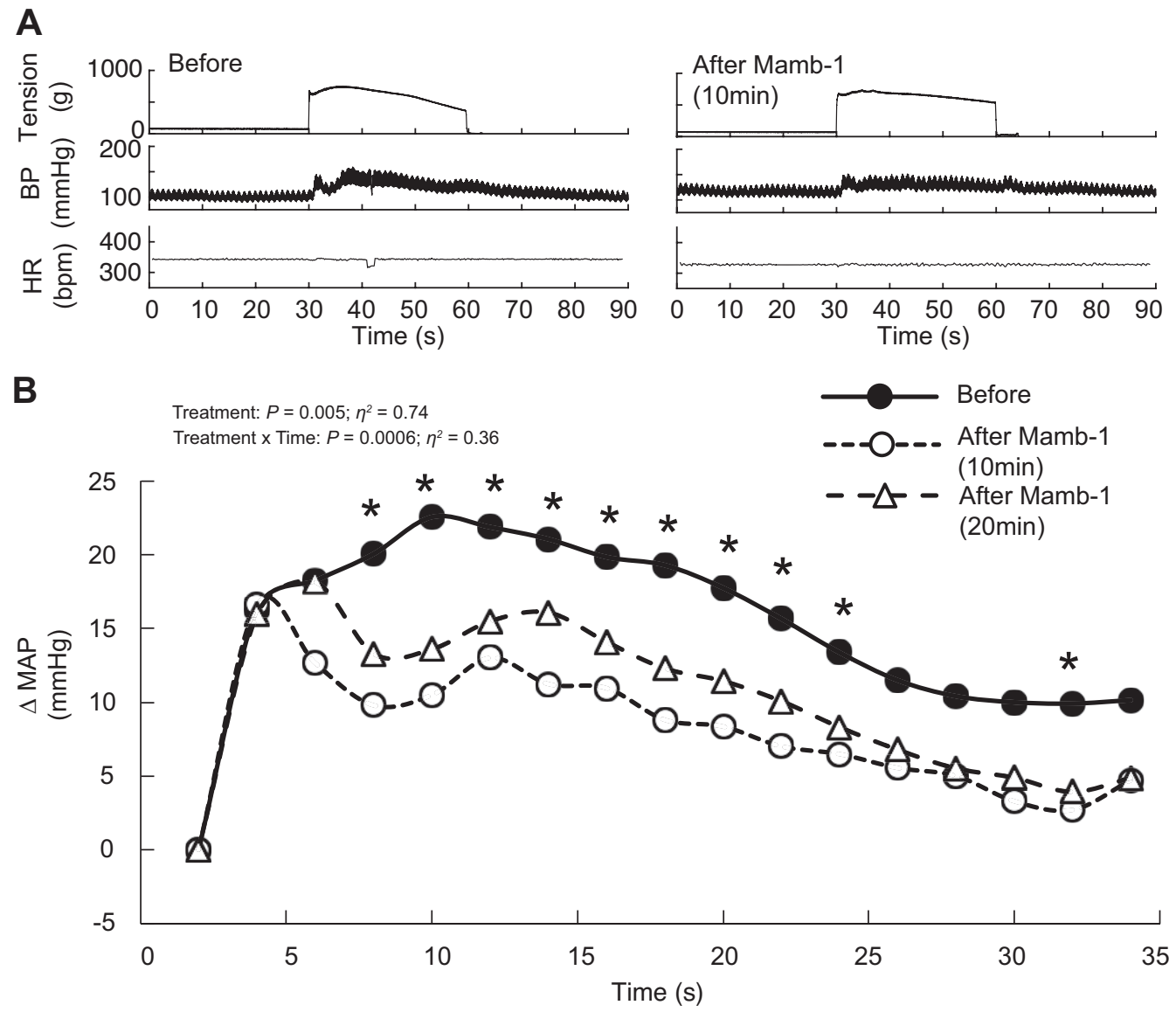

\section{Animal Characteristics, Wellness, and Sample Size}

Experiments were conducted at constant room air temperature $\left(21^{\circ} \mathrm{C}\right)$ on 56 male Sprague-Dawley rats (Charles River) weighing $350-550 \mathrm{~g}$.

Rats were housed within the central animal facility of the Penn State College of Medicine, with access to food and water ad libitum and exposure to a 12-h:12-h light-dark cycle. All attempts were made to minimize animal discomfort and pain.

\section{Surgical Procedures}

Each rat was anesthetized initially by inhalation of $4 \%$ isoflurane in oxygen. We started the surgical procedure only when the corneal reflex was abolished by the anesthesia and when pinching the hind paw did not produce a withdrawal reflex. The rat's trachea was first cannulated, and its lungs were mechanically ventilated (683, Harvard Apparatus, Holliston, MA). The amount of isoflurane was reduced to $2 \%$ for the rest of the surgery. The left and right common carotids and right jugular vein were cannulated using RenaPulse High Fidelity Pressure Tubing (RPT040, Braintree Scientific, Braintree, MA) to record arterial blood pressure (P23XL, Gould-Statham Instruments, Los Angeles CA), draw arterial blood samples, and inject drugs into the systemic circulation, respectively. We cannulated the left superficial epigastric artery (SUBL-140, Braintree Scientific), which is a side branch of the femoral artery. A snare (2.0 silk suture) was placed around the femoral artery and vein $\sim 0.5-1 \mathrm{~cm}$ upstream from the superficial epigastric artery and vein. When tightened, it partially trapped the solution in the hindlimb circulation. Finally, the muscular branch and saphenous arteries were ligated (4.0 silk suture) to increase the probability that the injectate accessed the triceps surae circulation.

For the contracting experiments, the tibial nerve was hooked with a bipolar stainless-steel electrode. The femur was attached to a small metal clamp, and the ankle was secured using zip ties to prevent knee and ankle movements, respectively, during the contracting or stretching procedures. The head of the rat was secured using a Kopf stereotaxic unit. The calcaneus bone was severed, and its attached Achilles tendon was connected to a force transducer (FT03, Grass Instrument, Quincy, MA) and a rack and pinion device.

Using a blunted spatula, we decerebrated the rat by sectioning the brain less than $1 \mathrm{~mm}$ rostral to the superior colliculus (16). The isoflurane was then discontinued, and the lungs were ventilated with room air. Blood arterial $\mathrm{PO}_{2}(100-150 \mathrm{mmHg}), \mathrm{PCO}_{2}(35-40 \mathrm{mmHg})$, and $\left[\mathrm{HCO}_{3}^{-}\right](22-26 \mathrm{mmol} / \mathrm{L})$ were kept within physiological range. Because the ASIC1a antagonist, psalmotoxin-1, has been found to potentiate ASIC1b at conditioning $\mathrm{pH}$ greater than 7.40 (8), particular attention was made to maintain arterial blood $\mathrm{pH}$ between 7.35 and 7.40. Body temperature was maintained around $37^{\circ} \mathrm{C}$ using a heating lamp. At the end of the experiment, the decerebrated rats were euthanized by intravenous injection of a supersaturated $\mathrm{KCl}$ solution.

\section{Description of ASICla Antagonists}

To determine the role played by ASIC1a in evoking the exercise pressor reflex, we injected the ASIC1a antagonists psalmotoxin-1 (PcTx-1) and mambalgin-1 (Mamb-1) into the hindlimb arterial circulation via the catheter placed in the superficial epigastric artery. PcTx-1 is a potent $\left(\mathrm{IC}_{50}=1 \mathrm{nM}\right)$ and selective homomeric ASIC1a inhibitor (20). At a higher concentration, PcTx-1 also blocks heteromeric ASIC1a/2b (IC $50=3 \mathrm{nM})(47)$ but has no effe1ct on ASIC2, ASIC3, or epithelial sodium channels (20). PcTx-1 has no inhibitory effect on ASIC1b. Mamb-1 is less potent (ASIC1a $\mathrm{IC}_{50}=55 \mathrm{nM}$ ) and less selective than PcTx-1 (15). At a higher concentration, Mamb-1 inhibits homomeric ASIC1b ( $\mathrm{IC}_{50}=192 \mathrm{nM}$ ) and heteromeric 
ASIC1a/2a $\left(\mathrm{IC}_{50}=246 \mathrm{nM}\right), \quad$ ASIC1a/2b $\left(\mathrm{IC}_{50}=61 \mathrm{nM}\right)$, and ASIC1a/1b $\left(\mathrm{IC}_{50}=72 \mathrm{nM}\right)(15)$.

\section{Experimental Procedures}

Contraction of the triceps surae muscles. Baseline tension of the triceps surae muscles was set at $60-100 \mathrm{~g}$. The stimulator output was set at a current intensity that evoked a twitch tension approximately equal to $90 \%$ of the maximal twitch tension ( $\sim 1.50$ times motor threshold). During static contraction, the tibial nerve was stimulated for $30 \mathrm{~s}$ at $40 \mathrm{~Hz}(0.01-\mathrm{ms}$ pulse duration) to reflexively increase arterial blood pressure (49). After $10 \mathrm{~min}$ of recovery, the snare around the femoral artery and vein was tightened, after which PcTx-1 $(200 \mathrm{ng} / \mathrm{kg} ; 100 \mu \mathrm{L})$ or Mamb-1 $(6.5 \mu \mathrm{g} / \mathrm{kg} ; 100 \mu \mathrm{L})$ was injected into the femoral artery using the superficial epigastric artery catheter. The snare was released $5 \mathrm{~min}$ after injecting the drug. After a reperfusion period of $5 \mathrm{~min}$ (i.e., $10 \mathrm{~min}$ after injecting the ASIC1a antagonists), the stimulation current intensity was adjusted if necessary and the muscle was contracted for $30 \mathrm{~s}$.

Stretch of the triceps surae muscles. We determined the effect of PcTx-1 and Mamb-1 on the pressor responses to stretch of the triceps surae muscles. The triceps surae muscles were stretched for $30 \mathrm{~s}$ by turning a rack and pinion attached to the Achilles tendon. After $10 \mathrm{~min}$ of recovery, the snare around the femoral artery and vein was tightened, and PcTx-1 (200 ng/kg; $100 \mu \mathrm{L})$ or Mamb-1 $(6.5 \mu \mathrm{g} / \mathrm{kg}$; $100 \mu \mathrm{L}$ ) was injected using the superficial epigastric artery catheter. The snare was released $5 \mathrm{~min}$ after injecting the drug. After a reperfusion period of $5 \mathrm{~min}$ (i.e., $10 \mathrm{~min}$ after injecting the ASIC1a antagonists), the stretching procedure was repeated.

Intra-arterial injections of lactic acid and diprotonated phosphate. We determined the effect of PcTx-1 and Mamb-1 on the pressor responses to injection of lactic acid or diprotonated phosphate. During these experiments, the rat was paralyzed by intravenous injection of pancuronium bromide $(0.2 \mathrm{mg} / \mathrm{mL} ; 0.2 \mathrm{~mL})$. Before injection of lactic acid or diprotonated phosphate, the snare placed around the femoral artery and vein was tightened to partially trap the solution in the hindlimb circulation. Then, lactic acid $(24 \mathrm{mM}$; pH 2.66; $100 \mu \mathrm{L})$ or diprotonated phosphate $(86 \mathrm{mM} ; \mathrm{pH} 6.0 ; 100 \mu \mathrm{L})$ was injected into the femoral artery to reflexively increase blood pressure. The snare was released 2 min after injecting the drug. After 10 min of recovery, PcTx-1 (200 ng/kg; $100 \mu \mathrm{L})$ or Mamb-1 (6.5 $\mu \mathrm{g} / \mathrm{kg} ; 100 \mu \mathrm{L})$ was injected again with the femoral snare tightened. The snare was released 5 min after injecting the drug. Following a reperfusion period of 5 min (i.e., $10 \mathrm{~min}$ after injecting the ASICla antagonists), lactic acid or diprotonated phosphate was reinjected.

\section{Control Experiments}

Control for electrical activation of group III and IV axons. To ensure that the tibial nerve stimulation did not electrically activate the axons of the group III and IV afferents, we paralyzed the rat with intravenous injection of pancuronium bromide $(1 \mathrm{mg} / \mathrm{mL} ; 0.2 \mathrm{~mL})$ and stimulated the tibial nerve for $30 \mathrm{~s}$ at $40 \mathrm{~Hz}$ with the highest stimulation parameters used to evoke contraction. If an increase in blood pressure was observed, the data were excluded from the data set.

Time control of ASICla inhibition. Two procedures were performed to ensure that the attenuating effect of PcTx-1 or Mamb-1 on a reflex pressor response was not confounded by deterioration of the preparation. First, before injecting the blocker, the pressor response to any stimulus was evoked at least two times to verify that the procedure was reproducible. Also, given that PcTx-1 is reversible within minutes (20), it would be expected that if the pressor response to one of the stimuli was reduced after injecting PcTx-1, the pressor response would recover. Therefore, if the pressor response evoked by one of the stimuli decreased after ASIC1a blockade, the procedure was repeated twice after $10 \mathrm{~min}$ of recovery (e.g., 20 and $30 \mathrm{~min}$ after injecting the ASIC1a antagonists). If no recovery was found or if the pressor response to one of the stimuli decreased further after the 30-min recovery period, we concluded that the decreased pressor response after ASIC1a blockade was due, at least in part, to the preparation deteriorating over time. The data were then excluded from the data set.

Control for blockade of ASICla within the central nervous system. We determined the effect of injecting PcTx-1 into the right jugular vein on the pressor responses to static contraction. Because the $\mathrm{IC}_{50}$ of PcTx-1 is low (i.e., $0.9 \mathrm{nM}$ ), a small amount of antagonist could still recirculate in the hindlimb circulation and have a peripheral inhibitory effect. Therefore, two snares were placed: one around the left iliac and one around the femoral artery. Both snares were tightened just before injecting the drug intravenously. This experiment was not conducted with Mamb-1, as Mamb-1 (molecular mass: 6,554

\section{Static Contraction}

A

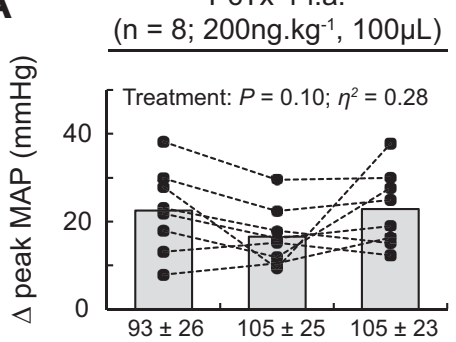

B

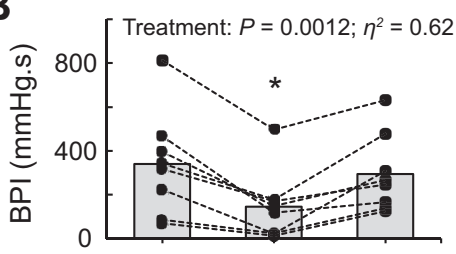

C

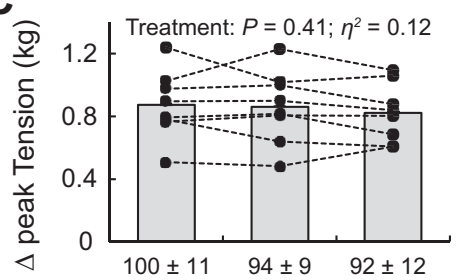

D

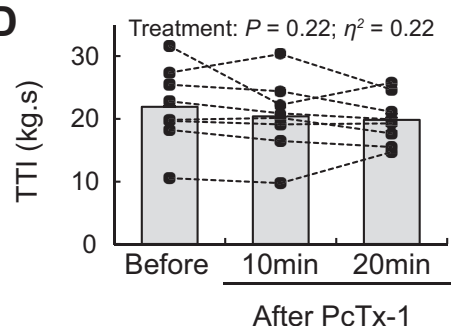

Mamb-1 i.a. $\underline{\left(\mathrm{n}=5 ; 6.5 \mu \mathrm{g} \cdot \mathrm{kg}^{-1}, 100 \mu \mathrm{L}\right)}$

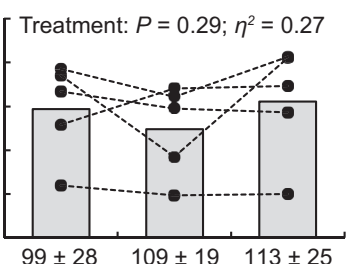

$99 \pm 28 \quad 109 \pm 19 \quad 113 \pm 25$

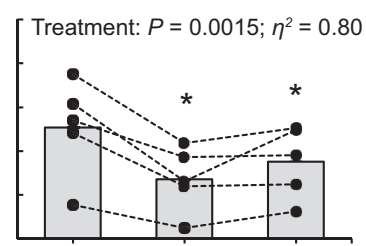

Treatment: $P=0.89 ; \eta^{2}=0.03$

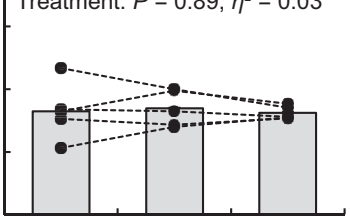

$82 \pm 4 \quad 78 \pm 5 \quad 81 \pm 3$

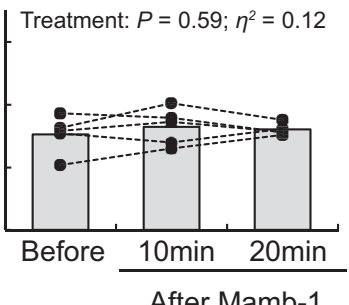

Fig. 3. Effect of acid-sensing ion channel 1a (ASIC1a) blockade on the pressor response to static contraction. Data are presented as individual (black dots) and group means (gray bars) for the peak increase in mean arterial blood pressure (MAP; $A$ ), blood pressure index (BPI; $B$ ), peak increase in tension $(C)$, and time-tension index (TTI; $D$ ) evoked by static contraction. Baseline means and standard deviations for blood pressure and tension (in g) are presented below the $x$-axis of their respective figures. Contractions were evoked before, at 10 $\mathrm{min}$ after, and at $20 \mathrm{~min}$ after psalmotoxin- $1(\mathrm{PcTx}-1 ; n=8 ; 200 \mathrm{ng} / \mathrm{kg}, 100$ $\mu \mathrm{L}$ ) or mambalgin-1 (Mamb-1;n=5;6.5 $\mu \mathrm{g} / \mathrm{kg}, 100 \mu \mathrm{L}$ ) injection into the superficial epigastric artery. ${ }^{*} P<0.05$, significant difference compared with before ASIC1a blockade. ia, intra-arterial. 
Table 2. Time control and reliability of the blood pressure, cardioaccelerator, and mechanical response to contraction, passive stretch, and chemical injections

\begin{tabular}{|c|c|c|c|c|c|c|c|}
\hline & $n$ & First Response & Second Response & $95 \% \mathrm{CI}$ & ICC & $P$ Value & Cohen's $d$ \\
\hline Contraction & 19 & & & & & & \\
\hline MAP, mmHg & & $23 \pm 11$ & $25 \pm 12$ & {$[-2: 6]$} & 0.72 & 0.23 & 0.17 \\
\hline $\mathrm{HR}$, beats/min & & $6.6 \pm 5.3$ & $7.0 \pm 5.4$ & {$[-1: 2]$} & 0.87 & 0.49 & 0.10 \\
\hline $\mathrm{BPI}, \mathrm{mmHg} \cdot \mathrm{s}$ & & $317 \pm 231$ & $300 \pm 242$ & {$[-75: 39]$} & 0.88 & 0.52 & 0.11 \\
\hline Tension, kg & & $0.73 \pm 0.18$ & $0.74 \pm 0.22$ & {$[-0.04: 0.07]$} & 0.86 & 0.49 & 0.12 \\
\hline $\mathrm{TTI}, \mathrm{kg} \cdot \mathrm{s}$ & & $17.6 \pm 0.5$ & $17.9 \pm 0.5$ & {$[-1.2: 1.9]$} & 0.81 & 0.67 & 0.07 \\
\hline Stretch & 11 & & & & & & \\
\hline MAP, mmHg & & $39 \pm 24$ & $40 \pm 24$ & {$[-4: 7]$} & 0.93 & 0.64 & 0.09 \\
\hline $\mathrm{HR}$, beats/min & & $4.5 \pm 2.4$ & $5.3 \pm 3.6$ & {$[-1: 3]$} & 0.25 & 0.37 & 0.23 \\
\hline $\mathrm{BPI}, \mathrm{mmHg} \cdot \mathrm{s}$ & & $426 \pm 317$ & $455 \pm 411$ & {$[-51: 110]$} & 0.93 & 0.43 & 0.19 \\
\hline Tension, kg & & $0.47 \pm 0.24$ & $0.46 \pm 0.24$ & {$[-0.02: 0.01]$} & 0.96 & 0.43 & 0.18 \\
\hline $\mathrm{TTI}, \mathrm{kg} \cdot \mathrm{s}$ & & $13.2 \pm 0.10$ & $13.4 \pm 0.10$ & {$[-0.3: 0.6]$} & 0.78 & 0.42 & 0.19 \\
\hline Lactic acid & 11 & & & & & & \\
\hline MAP, mmHg & & $41 \pm 19$ & $41 \pm 21$ & {$[-3: 3]$} & 0.98 & 0.85 & 0.01 \\
\hline HR, beats/min & & $4.8 \pm 1.3$ & $4.7 \pm 2.1$ & {$[3: 6]$} & 0.20 & 0.88 & 0.04 \\
\hline Diprotonated phosphate & 12 & & & & & & \\
\hline MAP, mmHg & & $41 \pm 26$ & $40 \pm 29$ & {$[-7: 7]$} & 0.92 & 0.96 & 0.06 \\
\hline $\mathrm{HR}$, beats/min & & $6.1 \pm 4.9$ & $5.7 \pm 5.2$ & {$[-2: 1]$} & 0.86 & 0.60 & 0.11 \\
\hline
\end{tabular}

Values are means $\pm \mathrm{SD}$ ( $n$, sample size) increase in heart rate evoked by static contraction, passive stretch, lactic acid, or diprotonated phosphate injections. Three rats from the contraction experiments were excluded from this analysis because it was not possible to compare two contractions of the same strength. A 95\% confidence interval is presented as the lower and upper boundary of the interval containing the true value of the difference between the first and second response. Effect size is presented as Cohen's $d$. BPI, blood pressure index; CI, confidence interval; HR, heart rate; ICC, intraclass correlation coefficient; MAP, mean arterial blood pressure; TTI, time-tension index.

Da) is a bigger peptide than PcTx-1 (molecular mass: 4,689 Da) and thus has a smaller chance to cross the blood-brain barrier.

Control for the effect of PcTx-1 activating an endogenous enkephalin pathway. ASIC1a blockade with PcTx-1 has been found to release Met-enkephalin, a $\mu$ - and $\delta$-opioid receptor agonist (38). To verify that the attenuating effect of PcTx-1 on the exercise pressor reflex was not caused by opioid receptor activation, we replicated the contraction experiments in rats pretreated with naloxone, a $\mu$ - and $\delta$-opioid antagonist (38). During these experiments, naloxone $(100 \mu \mathrm{g} / \mathrm{kg}, 100$ $\mu \mathrm{L}$ ) was infused for $10 \mathrm{~min}$ into the hindlimb circulation via the catheter placed in the superficial epigastric artery. The exercise pressor reflex was evoked by static contraction before infusing naloxone, $5 \mathrm{~min}$ after infusing naloxone, and 10 and $20 \mathrm{~min}$ after injecting PcTx-1.
Control for ASICla on vascular smooth muscle cells. ASIC1a has been found on vascular smooth muscle cells, and when stimulated by hydrogen ions, these cells will cause vasoconstriction (17). To determine if ASIC1a blockade reduced the exercise pressor reflex by increasing blood flow and washing out metabolic byproducts of contraction, we statically contracted the triceps surae muscles and measured their arterial blood flow by placing a Transonic flow probe around the popliteal artery. In these experiments, we stimulated the peripheral cut end of the sciatic nerve; we cut the nerve to prevent a sympathetic-induced vasoconstriction. Popliteal blood flow was recorded during static contraction and during the following hyperemic period.

Control that the drug was injected in the triceps surae muscles. To determine that injections into the hindlimb arterial circulation ac-

Table 3. The effect of ASICla blockade on the cardioaccelerator responses to chemical injection, contraction or passive stretch of the triceps surae muscles

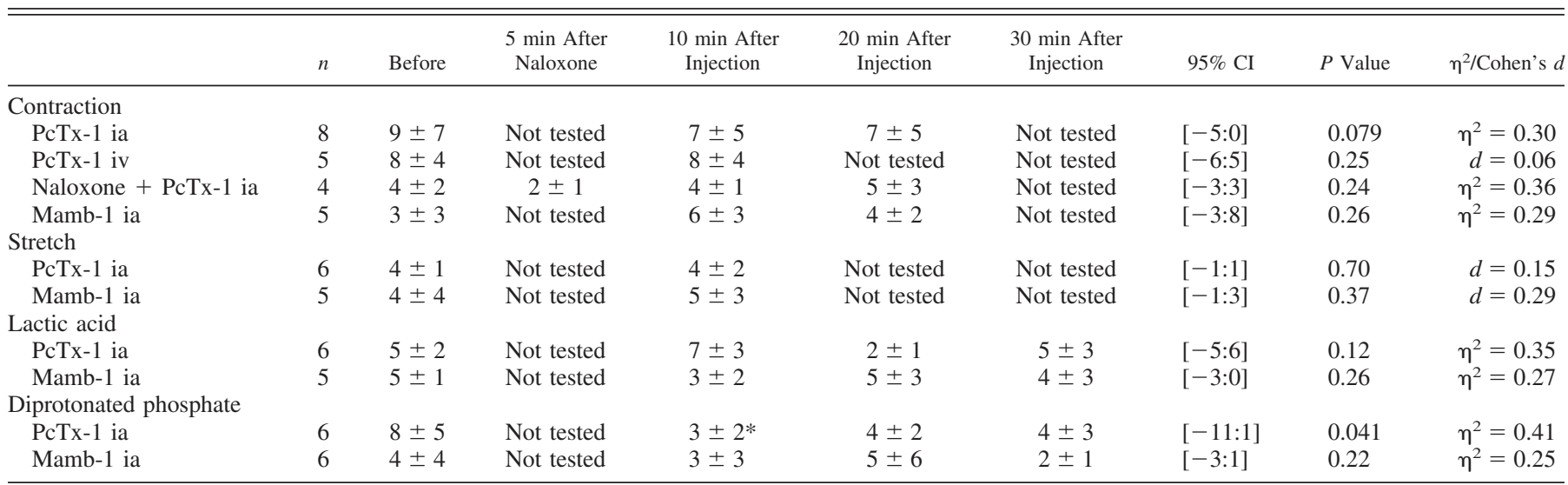

Values are means $\pm \mathrm{SD}$ ( $n$, sample size) increase in heart rate evoked by static contraction, passive stretch, lactic acid, or diprotonated phosphate injections A 95\% confidence interval is presented as the lower and upper boundary of the interval containing the true value of the effect of ASICla blockade at 10 min Effect size is presented as partial $\eta^{2}$ or Cohen's $d$ depending whether the statistical test was a one-way repeated-measures ANOVA or Student's paired $t$-test, respectively. ASIC1a, acid-sensing ion channel 1a; CI, confidence interval; ia, intra-arterial; iv, intravenous; Mamb-1, mambalgin-1; PcTx-1, psalmotoxin-1.* $P<$ 0.05 , significant difference between result compared with value before injection. 
cessed the triceps surae muscles, we injected $0.2 \mathrm{~mL}$ of Evans Blue dye into the superficial epigastric artery of each rat tested. We considered that the solution entered into the muscle when its belly was stained blue. If the color of the muscles did not change, we excluded the data from the study.

\section{Drug Preparation}

Lactic acid (Sigma-Aldrich), PcTx-1, Mamb-1, and naloxone (Alomone Laboratories) were dissolved in $0.9 \%$ saline and stored in 0.2 $\mathrm{mL}$ aliquots at $-20^{\circ} \mathrm{C}$. The dose of PcTx-1 (200 ng/kg, $\left.100 \mu \mathrm{L}\right)$ and Mamb-1 $(6.5 \mu \mathrm{g} / \mathrm{kg}, 100 \mu \mathrm{L})$ was chosen assuming that the drug would be diluted to reach concentrations of 1 and $25 \mathrm{nM}$ in the leg (20 $\mathrm{mL}$ total volume), respectively. Diprotonated phosphate was made by dissolving $153 \mathrm{mg}(43 \mathrm{mM})$ of $\mathrm{Na}_{2} \mathrm{HPO}_{4}$ and $129 \mathrm{mg}(43 \mathrm{mM})$ of $\mathrm{NaH}_{2} \mathrm{PO}_{4}$ into $25 \mathrm{~mL}$ of $10 \mathrm{mM}$ HEPES [4-(2-hydroxyethyl)-1piperazineethanesulfonic acid]. The $\mathrm{pH}$ of the solution was decreased to 6.0 by adding $\mathrm{HCl}$ and, if necessary, adjusted on a weekly basis.

\section{Data Analysis}

Tension and arterial blood pressure signals were amplified using Gould Universal Amplifier (Gould-Statham Instruments). Instantaneous blood flow (0.5 PSB and TS420, Transonic Systems, Ithaca, $\mathrm{NY}$ ) and all the other signals were displayed and recorded at $1 \mathrm{kHz}$ using an analog-to-digital converter (Micro1401 mkII, Cambridge Electronic Design, Cambridge, UK) and its associated commercially available software (Spike2, 7.20, RRID:SCR_000903, Cambridge Electronic Design). Heart rate was determined beat by beat from the arterial pressure pulse signal and expressed as beats per minute. To determine the effect of ASIC1a blockade on the pressor response to chemical injections, the peak increase in blood pressure was compared before and after injecting the antagonist. To determine the effect of ASIC1a blockade on the pressor response to static contraction or passive stretch, we calculated the peak pressor response and the increase in the blood pressure index. The blood pressure index was calculated by integrating the area under the curve during the $30-\mathrm{s}$ contraction or stretch period and then subtracting from this value the area under the curve measured during baseline (i.e., $1 \mathrm{~s}$ before the contraction or stretch, multiplied by 30 ). This variable provides an index of the entire pressor response, unlike the peak pressor response, which represents just the instantaneous maximal value. Using a similar method, we calculated the change in peak tension produced by the contraction or stretch, as well as the tension-time index (i.e., the equivalent of the blood pressure index for tension). The time course of the pressor response to static contraction or stretch was plotted by averaging the mean arterial blood pressure signal every $2 \mathrm{~s}$. To determine the effect of ASIC1a blockade on the blood flow response to contraction, the raw signal was averaged every $2 \mathrm{~s}$ and expressed as percent change from baseline. Mean change in blood flow was calculated by averaging the overall blood flow response during the static contraction period.

\section{Statistical Analysis}

Data are presented as means \pm SD. Using a Kolmogorov-Smirnov test, we verified that our samples respected a normal distribution. Reliability of the measures was evaluated by verifying that both samples did not differ using Student's paired $t$-test and by evaluating how strongly these samples resembled to each other using intraclass correlation coefficients (27). Reliability was considered excellent, good, fair, and poor when intraclass correlation coefficients were $>0.75,0.75-0.60,0.60-0.40$, and $<0.40$, respectively (9). The preto poststimulus (i.e., contraction, stretch, lactic acid, and diprotonated phosphate) change in peak pressor response, peak heart rate, blood pressure index, peak tension, and tension-time index were evaluated using Student's paired $t$-test. Student's paired $t$-test was also used to evaluate the pre- to postinjection effect of ASIC1a blockade on the different variables tested. In the cases in which serial measures were made before and after ASIC1a blockade (i.e., during lactic acid, diprotonated phosphate, and most contraction experiments), a oneway repeated-measures ANOVA was used to determine the effect of injecting PcTx-1 or Mamb-1. Finally, the effect of ASIC1a blockade on the time course of blood pressure was evaluated using two-way repeated measures ANOVA (treatment $\times$ time). The level of significance was set at $P<0.05$. When statistical difference was found, post hoc multiple-comparison analysis was performed using Tukey's honestly significant difference test. Effect size was calculated using Cohen's $d$ for Student's $t$ test or partial $\eta^{2}$ for ANOVA (10). A Cohen's $d$ index for effect size was considered as small, medium, or large when $d$ was close to $0.2,0.5$, or 0.8 , respectively (10). An $\eta^{2}$ for effect size was considered as small, medium, or large when $\eta^{2}$ was close to $0.02,0.13$, or 0.26 , respectively $(10)$. When individual data

Static Contraction

(PcTx-1 i.v., $\mathrm{n}=5$ )
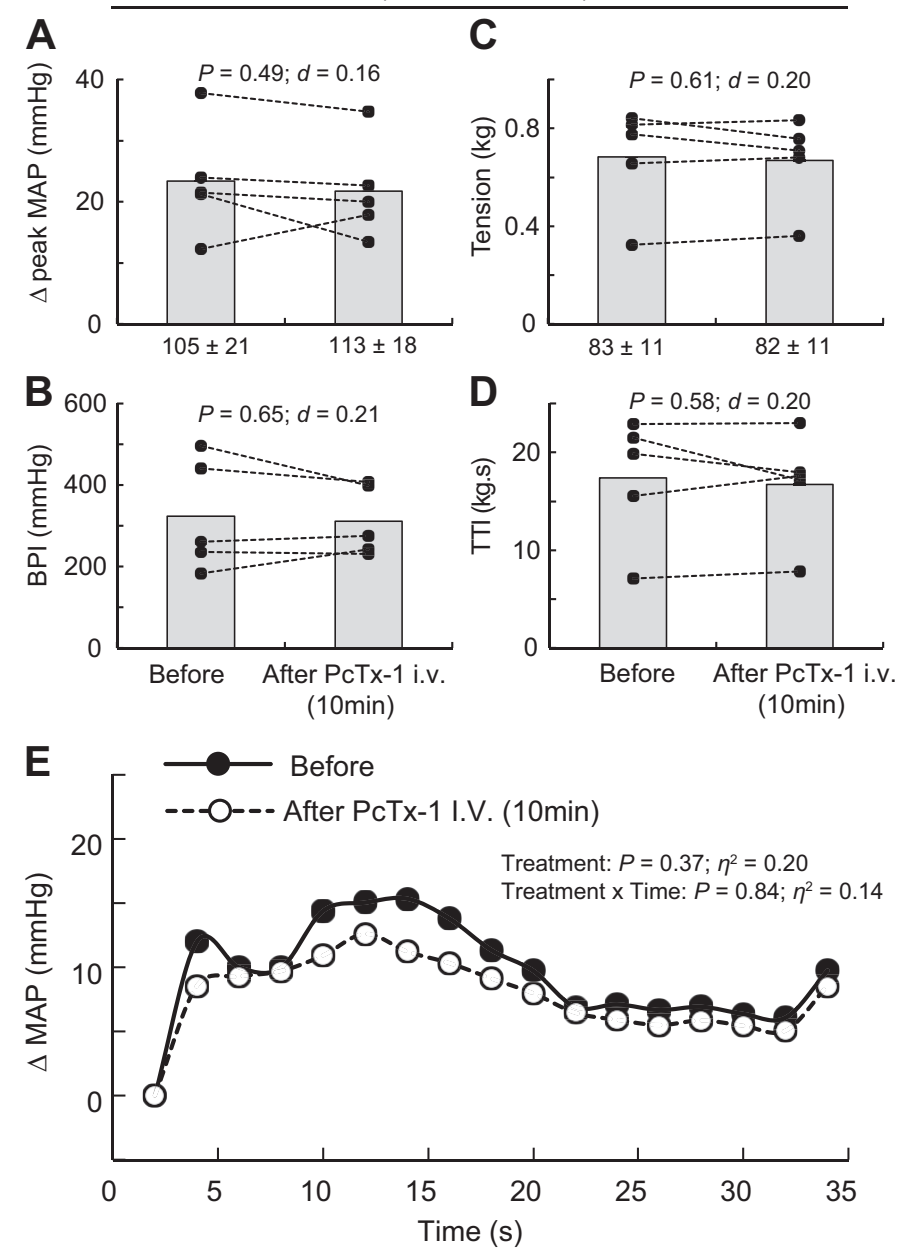

Fig. 4. Effect of injecting psalmotoxin-1 (PcTx-1) intravenously on the pressor response to static contraction. $A-D$ : data are presented as individual (black dots) and group means (gray bars) for the peak increase in mean arterial blood pressure (MAP), blood pressure index (BPI), peak increase in tension, and time-tension index (TTI) evoked by static contraction. Baseline means and standard deviations for blood pressure and tension (in $\mathrm{g}$ ) are presented below the $x$-axis of their respective figures. $E$ : the averaged increase in blood pressure over time. For clarity, error bars were omitted. The averaged time course of blood pressure includes $2 \mathrm{~s}$ of baseline, $30 \mathrm{~s}$ of contraction, and $2 \mathrm{~s}$ after the end of contraction. Contractions were evoked before and at $10 \mathrm{~min}$ following intravenous (iv) injection of PcTx-1 ( $n=5 ; 200 \mathrm{ng} / \mathrm{kg}, 100 \mu \mathrm{L})$ into the right jugular vein. 
were not presented, effect size was also calculated using $95 \%$ confidence intervals (13). Confidence intervals are presented as the lower and upper limit of the interval that should, if this experiment is repeated, contain the true value of the treated effect $95 \%$ of the time (13). Statistical analyses were conducted using Statistica 8.0 (RRID: SCR_014213, StatSoft, Tulsa, OK).

\section{RESULTS}

\section{Contraction Experiments}

Static contraction of the triceps surae muscles significantly increased blood pressure and heart rate compared with baseline $(n=22$, Table 1 , Figs. $1 A, 2 A$, and $3 A)$. Before injecting PcTx-1 $(n=8)$ or Mamb-1 $(n=5)$, good to excellent reliability was found for the pressor, cardioaccelerator, and tension response to static contraction (Table 2). Blocking ASIC1a by injecting PcTx-1 or Mamb-1 into the superficial epigastric artery significantly decreased the blood pressure index in each rat tested, whereas the peak pressor and cardioaccelerator responses were not significantly different from those before ASIC1a blockade (Fig. 3, $A$ and $B$, Table 3). Analysis of the averaged time course of the pressor response to contraction revealed that blocking ASIC1a with either PcTx-1 or Mamb-1 significantly attenuated the response $16 \mathrm{~s}$ and $8 \mathrm{~s}$ after the onset of contraction, respectively (Figs. $1 B$ and $2 B$ ). After 10 min of recovery, the inhibitory effect of PcTx-1 was no longer observable. The blood pressure index and the time course of blood pressure to contraction were not different than that before injecting PcTx-1 (Figs. $1 B, 2 B$, and 3B). A partial recovery was found after injecting Mamb-1, but the blood pressure index remained significantly lower than its preMamb-1 counterpart. Injecting PcTx-1 intravenously had no effect on the peak pressor response, blood pressure index, or increase in heart rate evoked by contraction $(n=5$, Fig. $4, A$, $B$, and $E$ ). Pretreating the rats with naloxone, a $\mu$ - and $\delta$-opioid antagonist (38), did not attenuate the effect of PcTx-1 on the blood pressure index evoked by contraction ( $n=4$, Fig. $5 B$ ). Finally, the mean or time course of blood flow was not affected by ASIC1a blockade while the triceps surae muscles were contracted by stimulating the peripheral cut end of the sciatic nerve (Fig. 6). For all experiments, the peak tension or the tension-time index was not different between before and after ASIC1a blockade (Fig. 3-6, $C$ and $D$ ).
Fig. 5. Effect of acid-sensing ion channel 1a blockade and $\mu$ and $\delta$-opioid receptor blockade on the pressor response to static contraction. $A-D$ : data are presented as individual (black dots) and group means (gray bars) for the peak increase in mean arterial blood pressure (MAP), blood pressure index (BPI), peak increase in tension, and time-tension index (TTI) evoked by static contraction. Baseline means and standard deviations for blood pressure and tension (in g) are presented below the $x$-axis of their respective figures. $E$ : averaged increase in blood pressure over time. For clarity, error bars were omitted. Averaged time course of blood pressure includes $2 \mathrm{~s}$ of baseline, 30 $\mathrm{s}$ of contraction, and $2 \mathrm{~s}$ after the end of contraction. Contractions were evoked before and at $10 \mathrm{~min}$ after naloxone infusion $(100 \mu \mathrm{g} / \mathrm{kg}, 100 \mu \mathrm{L}, 10 \mathrm{~min})$ and at $10 \mathrm{~min}$ and $20 \mathrm{~min}$ after psalmotoxin-1 (PcTx-1; $n=4 ; 200 \mathrm{ng} / \mathrm{kg}, 100 \mu \mathrm{L}$ ) injection. Both drugs were injected into the superficial epigastric artery. $* * P<0.01$, significant difference compared with before injections, after naloxone (5 min), and after PcTx-1 (20 min). ia, intra-articular.
Static contraction

(Naloxone i.a. + PcTx-1 i.a., $n=4$ )
A

$A$

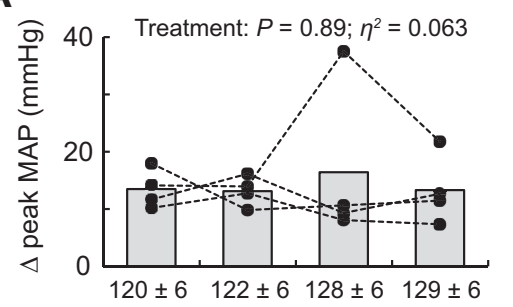

B

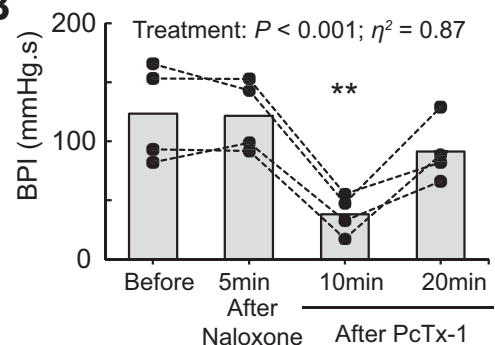

E

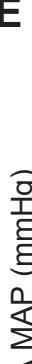

C

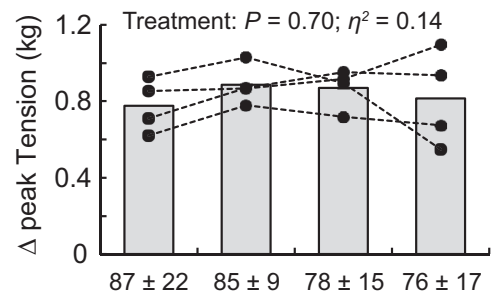

D

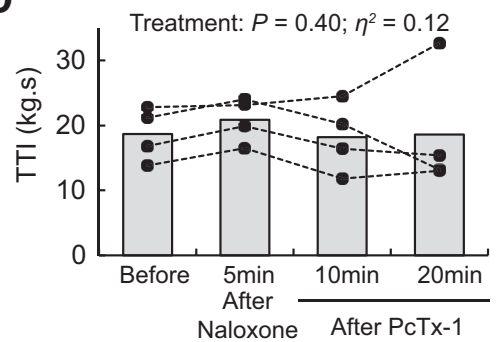

Treatment: $P=0.014 ; \eta^{2}=0.76$

Treatment $\mathrm{x}$ Time: $P=0.027 ; \eta^{2}=0.36$

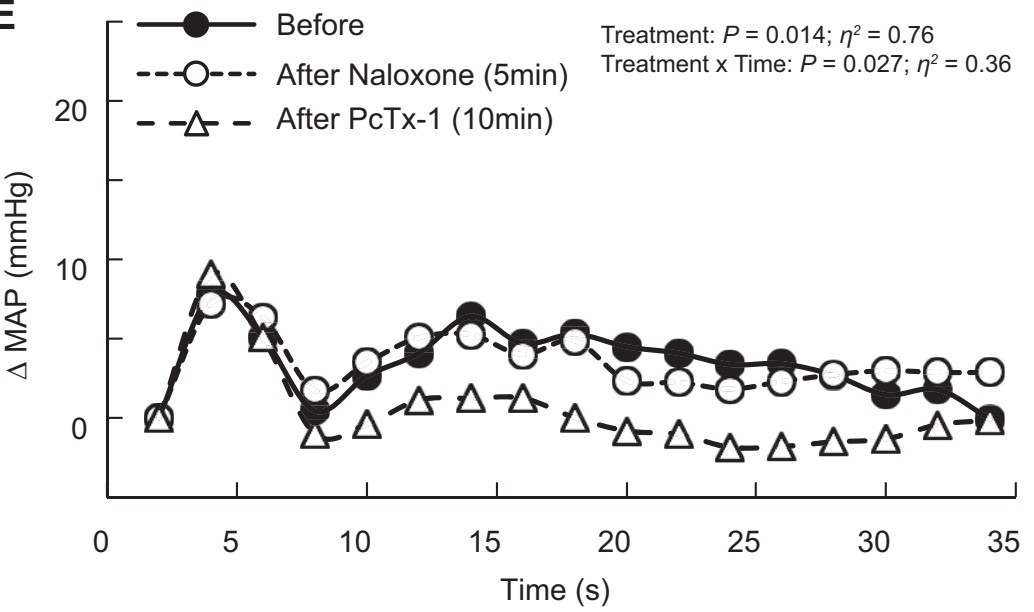



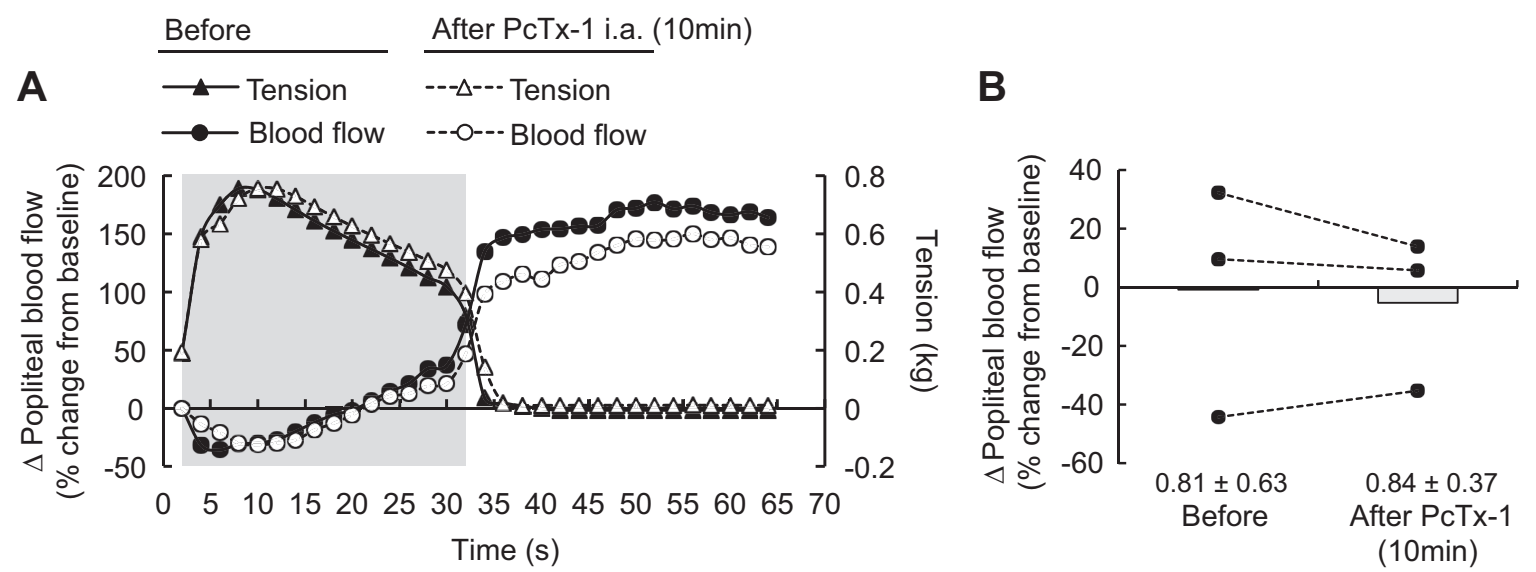

Fig. 6. Effect of acid-sensing ion channel 1a blockade on popliteal blood flow during contraction. A: the averaged time course of popliteal artery blood flow and tension development during static contraction and the following $30 \mathrm{~s}$ of recovery $(n=3)$. The gray shaded area represents the contraction period. $B$ : individual (black dots) and group means (gray bars) represent the mean percent changes in blood flow measured from the popliteal artery. Blood flow was calculated as the percent difference from baseline measurement. Baseline means and standard deviations for blood flow are presented below the $x$-axis of $B$. For clarity, error bars were omitted in $A$. The averaged time course of blood flow includes $2 \mathrm{~s}$ of baseline, $30 \mathrm{~s}$ of contraction, and $32 \mathrm{~s}$ after the end of contraction. Contractions were evoked before and at 10 min after psalmotoxin-1 (PcTx-1; $200 \mathrm{ng} / \mathrm{kg}, 100 \mu \mathrm{L}$ ) injection into the superficial epigastric artery. ia, intra-articular.

\section{Stretch Experiments}

Stretch of the triceps surae muscles significantly increased blood pressure and heart rate compared with baseline $(n=11$, Table 1, Fig. 7, $A-E)$. Before injecting PcTx-1 $(n=6)$ or Mamb-1 $(n=5)$, excellent reliability was found on the pressor and mechanical response to stretch (Table 2), whereas poor reliability was found on the cardioaccelerator response. Blocking ASIC1a had no significant effect on the peak pressor response, the blood pressure index, or the cardioaccelerator response to stretch (Fig. 7, $A, B$ and $E$ ). The peak tension or the tension-time index was not different between stretches (Fig. 7, $C$ and $D$ ).

\section{Lactic Acid and Diprotonated Phosphate Experiments}

Injecting $24 \mathrm{mM}$ lactic acid ( $n=11,100 \mu \mathrm{L} ; \mathrm{pH} 2.66)$ or 86 $\mathrm{mM}$ diprotonated phosphate $(n=12,100 \mu \mathrm{L} ; \mathrm{pH} 6.0)$ into the superficial epigastric artery significantly increased blood pressure and heart rate compared with baseline (Table 1, Fig. 8). Excellent reliability was found for the peak pressor responses to lactic acid or diprotonated phosphate injections (Table 2). Poor reliability was found on the cardioaccelerator response to lactic acid injection. PcTx-1 significantly decreased the peak pressor response to lactic acid and diprotonated phosphate injections 20 min after injecting the antagonist. Mamb-1 attenuated the peak pressor responses to both lactic acid and diprotonated phosphate $10 \mathrm{~min}$ after injecting the drug. Partial recovery of these attenuations was found $30 \mathrm{~min}$ after both PcTx-1 and Mamb-1.

\section{DISCUSSION}

We found that blocking ASIC1a with two structurally different antagonists attenuated the exercise pressor reflex evoked by static contraction of the triceps surae muscles. ASIC1a blockade also reduced the peak pressor responses to lactic acid and diprotonated phosphate injections into the arterial supply of the triceps surae muscles. Lactic acid and diprotonated phosphate are produced by static contraction and are believed, in part, to evoke the metabolic component of the exercise pressor reflex. On the other hand, ASIC1a blockade had little effect on the peak pressor response to contraction as well as the pressor response to passive stretch of the triceps surae muscles, both of which effects are thought to be determined by the mechanical component of the exercise pressor reflex. Our data therefore suggest that ASIC1a plays a key role in evoking the exercise pressor reflex in healthy rats by sensing lactic acid and diprotonated phosphate, which are metabolic byproducts of contraction.

In our experiments, blocking ASIC1a attenuated, in each rat tested, the exercise pressor reflex evoked by static contraction of the triceps surae muscles. The $64 \pm 18 \%$ decrease in the blood pressure index and time course of blood pressure following PcTx-1 injection is one of the first reports showing that blocking one population of receptors significantly attenuates the exercise pressor reflex in decerebrated rats with freely perfused muscles $(18,24,34,54-56)$. For example, Stone et al. (54) found that blocking ASIC3, EP4, or purinergic $2 \mathrm{X}$ receptors alone did not significantly attenuate the time course of the exercise pressor reflex, whereas blocking the three together had a significant inhibitory effect. Given that ASIC1a blockade did not entirely block the exercise pressor reflex, our data do not preclude the hypothesis of redundant mechanisms, but they nevertheless show that ASIC1a plays a key role in evoking the exercise pressor reflex in rats with freely perfused hindlimb muscles. This interpretation is strengthened by the fact that a similar result was found using Mamb-1, a structurally different ASIC1a antagonist.

As described above, ASIC1a blockade attenuated the time course of the pressor response to static contraction. This effect was observed 8-16 s after contraction onset, whereas this blockade had minimal, if any, effect beforehand (Figs. 1 and $2 B$ ). We speculate that at the onset of contraction, intramuscular metabolite concentrations were likely to be low, leading us to suggest that the associated rise in blood pressure was evoked by group III afferent mechanoreceptors (32). Our findings that ASIC1a blockade had no effect on the peak pressor response to contraction or on the pressor response to passive stretch support this conclusion. We also speculate that 


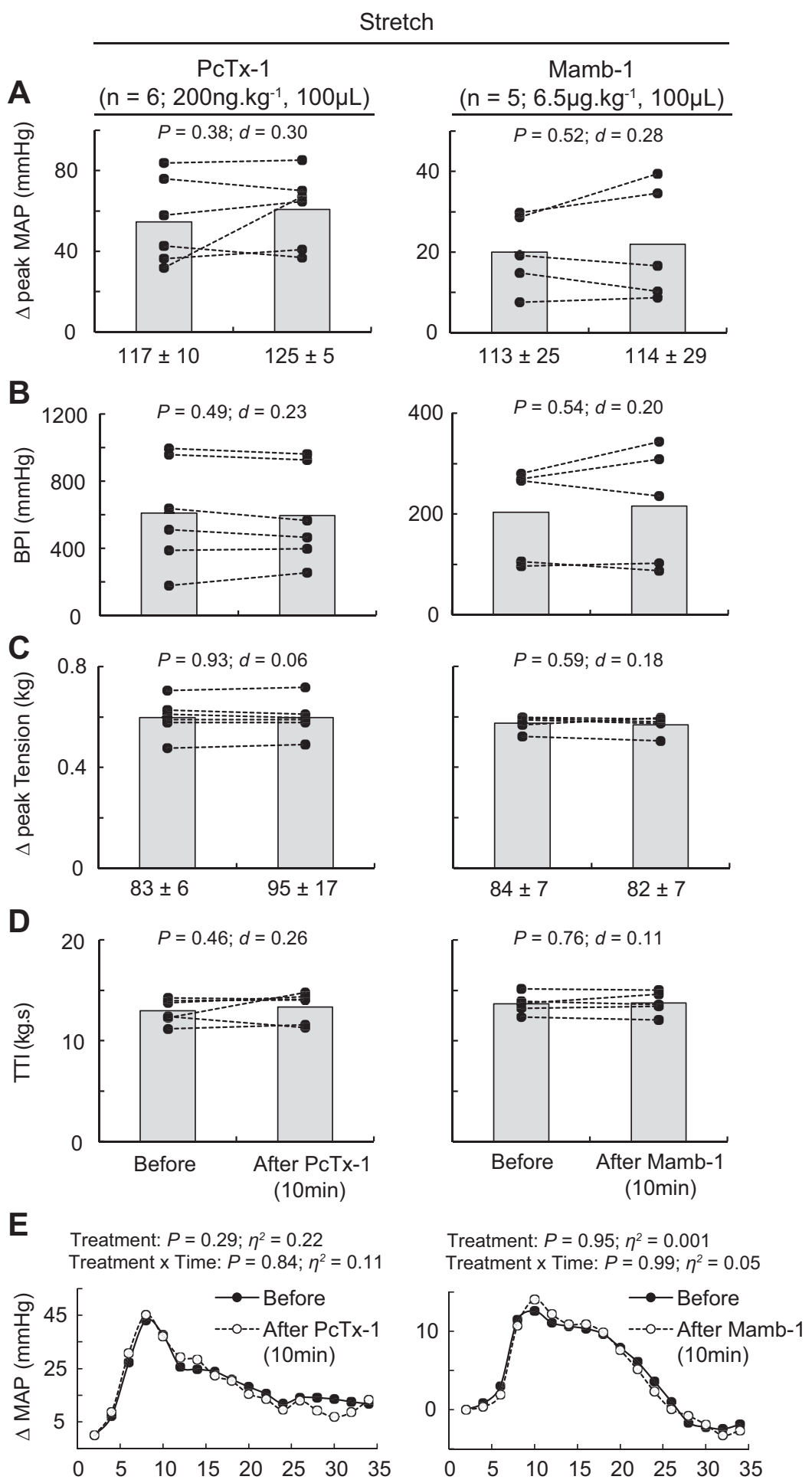

Fig. 7. Effect of acid-sensing ion channel 1a blockade on the pressor response to stretch. $A-D$ : data are presented as individual (black dots) and group means (gray bars) for the peak increase in mean arterial blood pressure (MAP), blood pressure index (BPI), peak increase in tension, and time-tension index (TTI) to stretch. Baseline means and standard deviations for blood pressure and tension are presented below the $x$-axis of their respective figures. $E$ : averaged increase in blood pressure over time. For clarity, error bars were omitted. The averaged time course of blood pressure includes $2 \mathrm{~s}$ of baseline, $30 \mathrm{~s}$ of stretch, and $2 \mathrm{~s}$ after the end of stretch. Stretches were evoked before and $10 \mathrm{~min}$ after psalmotoxin- 1 (PcTx-1;n=6;200 $\mathrm{ng} / \mathrm{kg}, 100 \mu \mathrm{L}$ ) or mambalgin-1 (Mamb-1; $n=5 ; 6.5 \mu \mathrm{g} / \mathrm{kg}$, $100 \mu \mathrm{L}$ ) injection into the superficial epigastric artery.

\section{D}



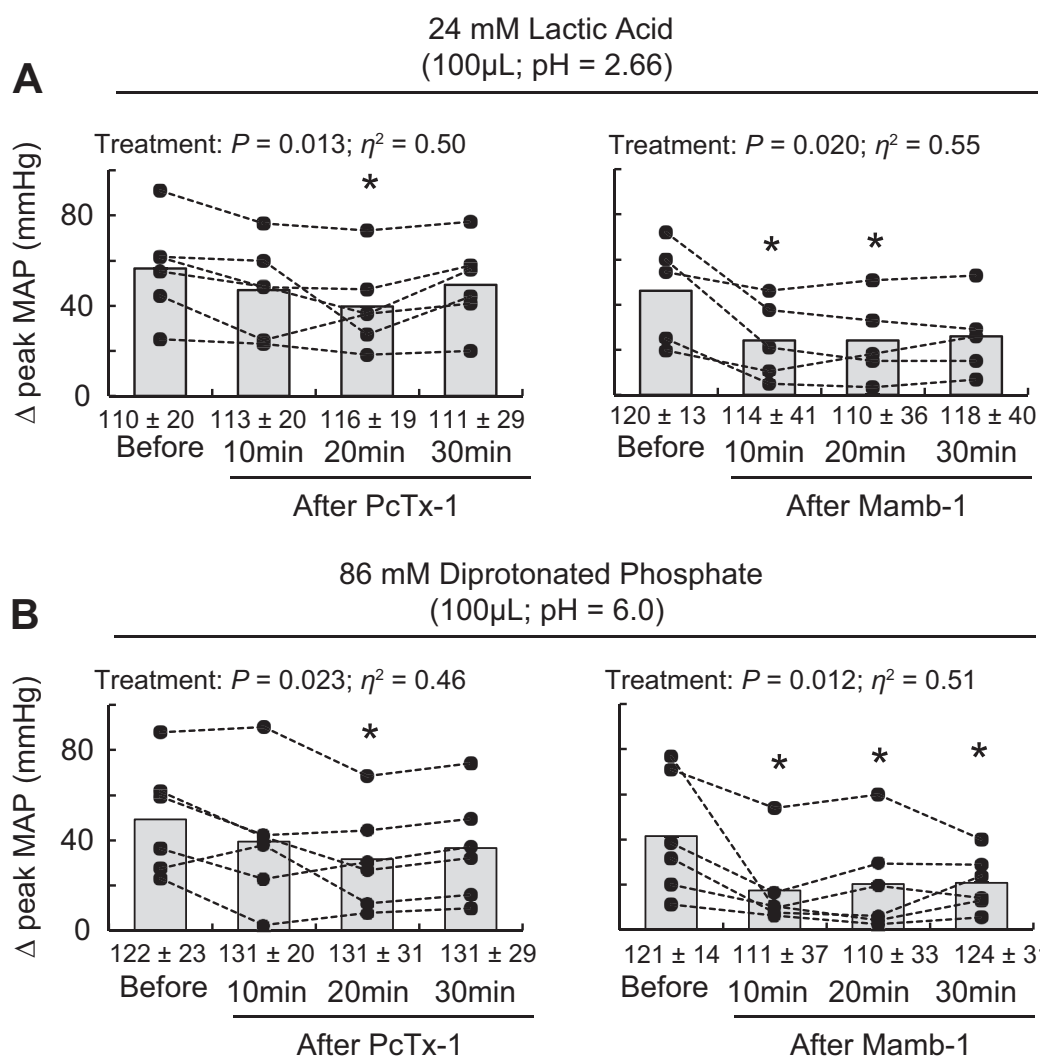

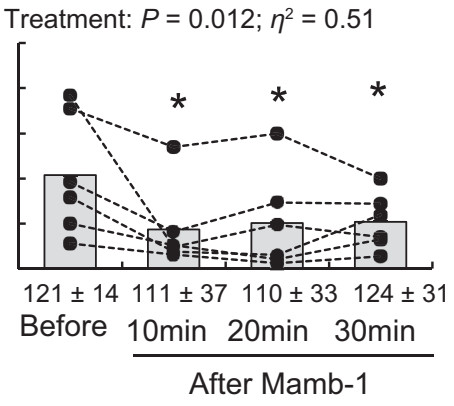

Fig. 8. Effect of acid-sensing ion channel 1a (ASIC1a) blockade on the pressor response to injection of lactic acid and diprotonated phosphate. Data are presented as individual (black dots) and group means (gray bars) for the peak pressor response to lactic acid (24 mM, $100 \mu \mathrm{L}, \mathrm{pH} 2.66)(A)$ and diprotonated phosphate ( $86 \mathrm{mM}, 100 \mu \mathrm{L}, \mathrm{pH} 6.0)(B)$ injections. Baseline means and standard deviations for blood pressure are presented below the $x$-axis. Lactic acid and diprotonated phosphate were injected into the superficial epigastric artery before and at 10 , 20 , and 30 min after psalmotoxin- 1 (PcTx-1; $n=6 ; 200 \mathrm{ng} / \mathrm{kg}$, $100 \mu \mathrm{L}$ ) or mambalgin-1 (Mamb-1; $n=5$ and $6 ; 6.5 \mu \mathrm{g} / \mathrm{kg}$, $100 \mu \mathrm{L}$ ) injection. $* P<0.05$, significant difference compared with before ASIC1a blockade. MAP, mean arterial pressure. perfused hindlimb muscles $(33,54,56)$. ASIC3 is considered by some investigators to be the most sensitive ASIC to $\mathrm{pH}$ decreases $(6,26,59)$, although others suggest that ASIC1a sensitivity might be comparable (4), if not more sensitive, to that of ASIC3 (5). Our experiments do not address this question, but we speculate that ASIC3 density in group IV afferents might have been too low to play a key role in evoking the exercise pressor reflex during static contraction. The only evidence supporting a role for ASIC3 in evoking the exercise pressor reflex in rats came from findings showing that blocking ASIC3 reduced the peak and time course of the pressor response to contraction in rats whose femoral arteries were ligated for $72 \mathrm{~h}$ (56). Quantification of ASIC proteins in the dorsal root ganglia innervating the hindlimbs of rats revealed that ASIC3 was greater in rats with ligated femoral arteries than it was in rats with freely perfused femoral arteries (21, $37)$. In contrast, ASIC1a was greater in rats with freely perfused femoral arteries than it was in rats with ligated femoral arteries (21).

\section{Methodological Considerations and Limits}

Several methodological considerations must be considered when considering our findings. First, for every variable in which a significant decrease was found after ASIC1a blockade, the response consistently recovered or was not further reduced 10 or 20 min after injecting the antagonists. These data demonstrate that the reductions observed were not due to degradation of the ability of the reflex to produce a pressor response.

Second, ASIC1a has been located in the central nervous system, raising the possibility that the depressive effect of ASIC1a blockade was due to inhibition of ASIC1a located in the brainstem or spinal cord $(7,57,58)$. Being large peptides (4,690 Da and 6,554 Da, respectively), PcTx-1 and Mamb-1 are not believed to cross the blood-brain barrier and are not expected to have an effect in the central nervous system when injected intra-arterially (14). Nevertheless, we eliminated the possibility of any central effect by showing that intravenous injection of PcTx-1 did not decrease the pressor response to contraction (Fig. 4, $A$ and $B$ ).

Third, PcTx-1 has been reported to have an analgesic effect because it activates an endogenous enkephalin pathway, leading to the production of Met-enkephalin, a $\mu$ - and $\delta$-opioid receptor agonist (38). This report raised the possibility that the depressive effect of PcTx-1 on the exercise pressor reflex in our experiments was due to opioid receptor activation rather than to ASIC1a blockade. We refuted that hypothesis by showing that a similar reduction in blood pressure index was found following ASIC1a blockade in rats pretreated with naloxone, a $\mu$ - and $\delta$-opioid receptor antagonist (Fig. 5B). Our interpretation is also supported by the fact that if PcTx-1 activated an endogenous enkephalin pathway, a significant decrease in the pressor response evoked by passive stretch would have been expected, given that this response is reduced following activation of $\delta$-opioid receptor with [D-Pen2,D-Pen5] enkephalin (DPDPE) (36).

Fourth, ASIC1a is located on vascular smooth muscle cells and when activated caused vasoconstriction (17). This mechanism raised the possibility that the reduced exercise pressor reflex found following ASIC1a blockade was the result of a local vasodilation that increased arterial blood flow to the triceps surae muscles, thereby washing out hydrogen ions. We refuted this possibility by showing that popliteal blood flow 
during contraction was the same before and after ASIC1a blockade (Fig. 6).

Finally, blocking ASIC1a with PcTx-1 had a significant inhibitory effect on the pressor response to lactic acid (pH 2.66) or diprotonated phosphate (pH 6.0) injection $20 \mathrm{~min}$ after injecting PcTx-1, whereas no effect was found at $10 \mathrm{~min}$ (unlike the contraction experiments). The absence of this inhibitory effect at $10 \mathrm{~min}$ after PcTx-1 injection can be explained by the fact that in some rats, a potentiating effect of PcTx-1 was found (Fig. 8). We interpret this finding as lactic acid and diprotonated phosphate activating ASIC1b, which opens at a pH of $6.5(4,7)$ and can be potentiated by PcTx-1 when applied at a conditioning $\mathrm{pH}$ of greater than 7.40 (8). Despite our attempts to maintain blood pH between 7.35 and 7.40 to limit this effect, ASIC1b activation might still have countered the inhibition of ASIC1a during the 10 min that followed ASIC1a blockade. This hypothesis is supported by the fact that Mamb-1, which does not potentiate ASIC1b (15), depressed the pressor response to lactic acid and diprotonated phosphate injection at 10 min following injecting the antagonist.

\section{Conclusions and Perspective}

We found for the first time that ASIC1a plays a key role in evoking the exercise pressor reflex in decerebrated rats with freely perfused hindlimb muscles. This channel appears to be key for transducing the increases in lactic acid and diprotonated phosphate concentrations that arise during exercise. Further in vivo studies using afferent recording and/or ASIC1a blockade in a pathological model are warranted to better understand the role of ASICla and the underlying mechanisms that are responsible for evoking the exercise pressor reflex during exercise.

\section{GRANTS}

This study was funded by National Institutes of Health Grants R01-AR059397 and P01-HL-134609.

\section{DISCLOSURES}

No conflicts of interest, financial or otherwise, are declared by the authors.

\section{AUTHOR CONTRIBUTIONS}

G.P.D. and M.P.K. conceived and designed research; G.P.D. performed experiments; G.P.D. analyzed data; G.P.D., J.S.K., J.A.E., and M.P.K. interpreted results of experiments; G.P.D. prepared figures; G.P.D. drafted manuscript; G.P.D., J.S.K., J.A.E., and M.P.K. edited and revised manuscript; G.P.D., J.S.K., J.A.E., and M.P.K. approved final version of manuscript.

\section{REFERENCES}

1. Alam M, Smirk FH. Observations in man upon a blood pressure raising reflex arising from the voluntary muscles. J Physiol 89: 372-383, 1937. doi:10.1113/jphysiol.1937.sp003485.

2. Allen DG, Lamb GD, Westerblad H. Skeletal muscle fatigue: cellular mechanisms. Physiol Rev 88: 287-332, 2008. doi:10.1152/physrev.00015. 2007.

3. Amann M, Runnels S, Morgan DE, Trinity JD, Fjeldstad AS, Wray DW, Reese VR, Richardson RS. On the contribution of group III and IV muscle afferents to the circulatory response to rhythmic exercise in humans. J Physiol 589: 3855-3866, 2011. doi:10.1113/jphysiol.2011. 209353.

4. Babini E, Paukert M, Geisler HS, Gründer S. Alternative splicing and interaction with di- and polyvalent cations control the dynamic range of acid-sensing ion channel 1 (ASIC1). J Biol Chem 277: 41597-41603, 2002. doi:10.1074/jbc.M205877200.
5. Benson CJ, Xie J, Wemmie JA, Price MP, Henss JM, Welsh MJ, Snyder PM. Heteromultimers of $\mathrm{DEG} / \mathrm{ENaC}$ subunits form $\mathrm{H}+$-gated channels in mouse sensory neurons. Proc Natl Acad Sci USA 99: $2338-$ 2343, 2002. [Erratum in Proc Natl Acad Sci USA 99: 4752, 2002.] doi:10.1073/pnas.032678399.

6. Birdsong WT, Fierro L, Williams FG, Spelta V, Naves LA, Knowles M, Marsh-Haffner J, Adelman JP, Almers W, Elde RP, McCleskey EW. Sensing muscle ischemia: coincident detection of acid and ATP via interplay of two ion channels. Neuron 68: 739-749, 2010. doi:10.1016/j. neuron.2010.09.029.

7. Chen CC, England S, Akopian AN, Wood JN. A sensory neuronspecific, proton-gated ion channel. Proc Natl Acad Sci USA 95: 1024010245, 1998. doi:10.1073/pnas.95.17.10240.

8. Chen $\mathbf{X}$, Kalbacher $\mathbf{H}$, Gründer S. Interaction of acid-sensing ion channel (ASIC) 1 with the tarantula toxin psalmotoxin 1 is state dependent. J Gen Physiol 127: 267-276, 2006. doi:10.1085/jgp.200509409.

9. Cicchetti DV. Guidelines, criteria, and rules of thumb for evaluating normed and standardized assessment instruments in psychology. Psychol Assess 6: 284-290, 1994. doi:10.1037/1040-3590.6.4.284.

10. Cohen J. Statistical Power Analysis for the Behavioral Sciences. New York: Academic, 1977.

11. Coote JH, Hilton SM, Perez-Gonzalez JF. The reflex nature of the pressor response to muscular exercise. J Physiol 215: 789-804, 1971. doi:10.1113/jphysiol.1971.sp009498.

12. Cortright DN, Crandall M, Sanchez JF, Zou T, Krause JE, White G. The tissue distribution and functional characterization of human VR1. Biochem Biophys Res Commun 281: 1183-1189, 2001. doi:10.1006/bbrc. 2001.4482.

13. Curran-Everett D. Explorations in statistics: confidence intervals. $A d v$ Physiol Educ 33: 87-90, 2009. doi:10.1152/advan.00006.2009.

14. Dibas J, Al-Saad H, Dibas A. Basics on the use of acid-sensing ion channels' inhibitors as therapeutics. Neural Regen Res 14: 395-398, 2019. doi:10.4103/1673-5374.245466.

15. Diochot S, Baron A, Salinas M, Douguet D, Scarzello S, Dabert-Gay AS, Debayle D, Friend V, Alloui A, Lazdunski M, Lingueglia E. Black mamba venom peptides target acid-sensing ion channels to abolish pain. Nature 490: 552-555, 2012. doi:10.1038/nature11494.

16. Dobson KL, Harris J. A detailed surgical method for mechanical decerebration of the rat. Exp Physiol 97: 693-698, 2012. doi:10.1113/ expphysiol.2012.064840.

17. Drummond HA, Xiang L, Chade AR, Hester R. Enhanced maximal exercise capacity, vasodilation to electrical muscle contraction, and hind limb vascular density in ASIC1a null mice. Physiol Rep 5: e13368, 2017. doi:10.14814/phy2.13368.

18. Ducrocq GP, Estrada JA, Kim JS, Kaufman MP. Blocking the transient receptor potential vanilloid-1 does not reduce the exercise pressor reflex in healthy rats. Am J Physiol Regul Integr Comp Physiol 317: R576-R587, 2019. doi:10.1152/ajpregu.00174.2019.

20. Escoubas P, De Weille JR, Lecoq A, Diochot S, Waldmann R, Champigny G, Moinier D, Ménez A, Lazdunski M. Isolation of a tarantula toxin specific for a class of proton-gated $\mathrm{Na}+$ channels. $J$ Biol Chem 275: 25116-25121, 2000. doi:10.1074/jbc.M003643200.

21. Farrag M, Drobish JK, Puhl HL, Kim JS, Herold PB, Kaufman MP, Ruiz-Velasco V. Endomorphins potentiate ASIC currents and enhance the lactic acid-mediated increase in arterial blood pressure-effects amplified in hindlimb ischemia. J Physiol, 2017. doi:10.1113/JP275058.

22. Gründer S, Geissler HS, Bässler EL, Ruppersberg JP. A new member of acid-sensing ion channels from pituitary gland. Neuroreport 11: 16071611, 2000. doi:10.1097/00001756-200006050-00003.

23. Hanukoglu I. ASIC and $\mathrm{ENaC}$ type sodium channels: conformational states and the structures of the ion selectivity filters. FEBS J 284: 525-545, 2017. doi:10.1111/febs.13840.

24. Hayes SG, Kindig AE, Kaufman MP. Blockade of acid sensing ion channels attenuates the exercise pressor reflex in cats. $J$ Physiol 581: 1271-1282, 2007. doi:10.1113/jphysiol.2007.129197.

25. Hayes SG, McCord JL, Rainier J, Liu Z, Kaufman MP. Role played by acid-sensitive ion channels in evoking the exercise pressor reflex. Am $J$ Physiol Heart Circ Physiol 295: H1720-H1725, 2008. doi:10.1152/ ajpheart.00623.2008.

26. Hesselager M, Timmermann DB, Ahring PK. pH dependency and desensitization kinetics of heterologously expressed combinations of acidsensing ion channel subunits. J Biol Chem 279: 11006-11015, 2004. doi:10.1074/jbc.M313507200. 
27. Hopkins WG. Measures of reliability in sports medicine and science. Sports Med 30: 1-15, 2000. doi:10.2165/00007256-200030010-00001.

28. Immke DC, McCleskey EW. Lactate enhances the acid-sensing $\mathrm{Na}+$ channel on ischemia-sensing neurons. Nat Neurosci 4: 869-870, 2001. doi:10.1038/nn0901-869.

29. Immke DC, McCleskey EW. Protons open acid-sensing ion channels by catalyzing relief of Ca2 + blockade. Neuron 37: 75-84, 2003. doi:10.1016/ S0896-6273(02)01130-3.

30. Jankowski MP, Rau KK, Ekmann KM, Anderson CE, Koerber HR. Comprehensive phenotyping of group III and IV muscle afferents in mouse. J Neurophysiol 109: 2374-2381, 2013. doi:10.1152/jn.01067. 2012.

31. Kaufman MP, Iwamoto GA, Longhurst JC, Mitchell JH. Effects of capsaicin and bradykinin on afferent fibers with ending in skeletal muscle. Circ Res 50: 133-139, 1982. doi:10.1161/01.RES.50.1.133.

32. Kaufman MP, Longhurst JC, Rybicki KJ, Wallach JH, Mitchell JH. Effects of static muscular contraction on impulse activity of groups III and IV afferents in cats. J Appl Physiol 55: 105-112, 1983. doi:10.1152/jappl. 1983.55.1.105.

33. Kim JS, Harms JE, Ruiz-Velasco V, Kaufman MP. Effect of knockout of the ASIC3 on cardiovascular reflexes arising from hindlimb muscle in decerebrated rats. Am J Physiol Regul Integr Comp Physiol 317: R641R648, 2019. doi:10.1152/ajpregu.00148.2019.

34. Kindig AE, Heller TB, Kaufman MP. VR-1 receptor blockade attenuates the pressor response to capsaicin but has no effect on the pressor response to contraction in cats. Am J Physiol Heart Circ Physiol 288: H1867-H1873, 2005. doi:10.1152/ajpheart.00735.2004.

35. Kniffki KD, Mense S, Schmidt RF. Responses of group IV afferent units from skeletal muscle to stretch, contraction and chemical stimulation. Exp Brain Res 31: 511-522, 1978. doi:10.1007/BF00239809.

36. Leal AK, Yamauchi K, Kim J, Ruiz-Velasco V, Kaufman MP. Peripheral $\delta$-opioid receptors attenuate the exercise pressor reflex. Am J Physiol Heart Circ Physiol 305: H1246-H1255, 2013. doi:10.1152/ajpheart. 00116.2013 .

37. Liu J, Gao Z, Li J. Femoral artery occlusion increases expression of ASIC3 in dorsal root ganglion neurons. Am J Physiol Heart Circ Physiol 299: H1357-H1364, 2010. doi:10.1152/ajpheart.00612.2010.

38. Mazzuca M, Heurteaux C, Alloui A, Diochot S, Baron A, Voilley N, Blondeau N, Escoubas P, Gélot A, Cupo A, Zimmer A, Zimmer AM, Eschalier A, Lazdunski M. A tarantula peptide against pain via ASIC1a channels and opioid mechanisms. Nat Neurosci 10: 943-945, 2007. doi:10.1038/nn1940.

39. McCloskey DI, Mitchell JH. Reflex cardiovascular and respiratory responses originating in exercising muscle. J Physiol 224: 173-186, 1972. doi:10.1113/jphysiol.1972.sp009887.

40. Mense S, Meyer H. Different types of slowly conducting afferent units in cat skeletal muscle and tendon. J Physiol 363: 403-417, 1985. doi:10. 1113/jphysiol.1985.sp015718.

41. Mitchell JH, Kaufman MP, Iwamoto GA. The exercise pressor reflex: its cardiovascular effects, afferent mechanisms, and central pathways. Annu Rev Physiol 45: 229-242, 1983. doi:10.1146/annurev.ph.45.030183. 001305.

42. Mizuno M, Murphy MN, Mitchell JH, Smith SA. Antagonism of the TRPv1 receptor partially corrects muscle metaboreflex overactivity in spontaneously hypertensive rats. J Physiol 589: 6191-6204, 2011. doi:10. 1113/jphysiol.2011.214429.

43. O'Leary DS, Augustyniak RA, Ansorge EJ, Collins HL. Muscle metaboreflex improves $\mathrm{O} 2$ delivery to ischemic active skeletal muscle. Am J Physiol 276: H1399-H1403, 1999.
44. Paintal AS. Functional analysis of group III afferent fibres of mammalian muscles. J Physiol 152: 250-270, 1960. doi:10.1113/jphysiol.1960. sp006486.

45. Pan HL, Stebbins CL, Longhurst JC. Bradykinin contributes to the exercise pressor reflex: mechanism of action. J Appl Physiol (1985) 75: 2061-2068, 1993. doi:10.1152/jappl.1993.75.5.2061.

46. Rotto DM, Kaufman MP. Effect of metabolic products of muscular contraction on discharge of group III and IV afferents. J Appl Physiol (1985) 64: 2306-2313, 1988. doi:10.1152/jappl.1988.64.6.2306.

47. Sherwood TW, Lee KG, Gormley MG, Askwith CC. Heteromeric acid-sensing ion channels (ASICs) composed of ASIC2b and ASIC1a display novel channel properties and contribute to acidosis-induced neuronal death. J Neurosci 31: 9723-9734, 2011. doi:10.1523/JNEUROSCI. 1665-11.2011.

48. Smith SA, Leal AK, Williams MA, Murphy MN, Mitchell JH, Garry MG. The TRPV1 receptor is a mediator of the exercise pressor reflex in rats. J Physiol 588: 1179-1189, 2010. doi:10.1113/jphysiol.2009.184952.

49. Smith SA, Mitchell JH, Garry MG. Electrically induced static exercise elicits a pressor response in the decerebrate rat. J Physiol 537: 961-970, 2001. doi:10.1113/jphysiol.2001.012918.

50. Stacey MJ. Free nerve endings in skeletal muscle of the cat. J Anat 105: 231-254, 1969.

51. Stebbins CL, Brown B, Levin D, Longhurst JC. Reflex effect of skeletal muscle mechanoreceptor stimulation on the cardiovascular system. J Appl Physiol (1985) 65: 1539-1547, 1988. doi:10.1152/jappl.1988.65.4.1539.

52. Stebbins CL, Carretero OA, Mindroiu T, Longhurst JC. Bradykinin release from contracting skeletal muscle of the cat. J Appl Physiol (1985) 69: 1225-1230, 1990. doi:10.1152/jappl.1990.69.4.1225.

53. Stebbins CL, Longhurst JC. Bradykinin in reflex cardiovascular responses to static muscular contraction. J Appl Physiol (1985) 61: 271-279, 1986. doi:10.1152/jappl.1986.61.1.271.

54. Stone AJ, Copp SW, Kim JS, Kaufman MP. Combined, but not individual, blockade of ASIC3, P2X, and EP4 receptors attenuates the exercise pressor reflex in rats with freely perfused hindlimb muscles. $J$ Appl Physiol (1985) 119: 1330-1336, 2015. doi:10.1152/japplphysiol. 00630.2015 .

55. Tsuchimochi H, McCord JL, Hayes SG, Koba S, Kaufman MP. Chronic femoral artery occlusion augments exercise pressor reflex in decerebrated rats. Am J Physiol Heart Circ Physiol 299: H106-H113, 2010. doi:10.1152/ajpheart.00141.2010.

56. Tsuchimochi H, Yamauchi K, McCord JL, Kaufman MP. Blockade of acid sensing ion channels attenuates the augmented exercise pressor reflex in rats with chronic femoral artery occlusion. J Physiol 589: 6173-6189, 2011. doi:10.1113/jphysiol.2011.217851.

57. Voilley N, de Weille J, Mamet J, Lazdunski M. Nonsteroid antiinflammatory drugs inhibit both the activity and the inflammation-induced expression of acid-sensing ion channels in nociceptors. J Neurosci 21: 8026-8033, 2001. doi:10.1523/JNEUROSCI.21-20-08026.2001.

57a.von Düring M. Andres KH. Topography and ultrastructure of group III and IV nerve terminals of the cat's gastrocnemius-soleus muscle. In: The Primary Afferent Neuron. Boston, MA: Springer, 1990, p. 35-41.

58. Waldmann R, Champigny G, Bassilana F, Heurteaux C, Lazdunski M. A proton-gated cation channel involved in acid-sensing. Nature 386: 173-177, 1997. doi:10.1038/386173a0.

59. Wemmie JA, Taugher RJ, Kreple CJ. Acid-sensing ion channels in pain and disease. Nat Rev Neurosci 14: 461-471, 2013. doi:10.1038/nrn3529. 